\title{
AROUSAL SAFETY LEADING TO PURCHASE INTENTION; THE ROLE OF MODERATING AND MEDIATING VARIABLES IN STRUCTURAL MODEL
}

\author{
Irfan Hameed* \\ Bibi Zainab** \\ Syed Jazib Shamim ${ }^{* * *}$
}

\begin{abstract}
The effect of arousal safety has been analyzed on purchase intention, then attitude towards the advertisement and attitude towards the brand have been incorporated as intervening variables between the relationships. The interaction effect of self-monitoring and message arguments have also been taken in to consideration for better understanding of the consumer's response. The data has been gathered from 206 respondents by using purposive sampling method. The research instrument was comprised of summated rating/additive scale (likert scale) and semantic differential scaling. Confirmatory Factor Analysis has been applied after the application of preliminary tests on the data. Structure Equation Modeling and moderation and mediation analysis have also been applied to test the hypotheses. Arousal safety in the advertisements shape consumers response and it proved to be a fully mediated model. Self-monitoring also probes the relationship. Message arguments haven't had any affect as moderator, hence can be used as a focal predictor. The study is a starting point for future research to provide a coherent methodology for capturing the necessary data, processing the underlying information and evaluating the effects of arousal safety in advertisements. The study extends the field of advertising in the direction of arousal safety (Humor) effects. In comparison to previous research, empirical evidence on the arousal safety in television advertising and purchase intention in relation with moderating and mediating variables is provided.
\end{abstract}

Keywords: Arousal safety, humor in advertising, purchase intention, attitude towards the advertisement, attitude towards the brand

\section{Introduction}

Researchers have recommended that arousal-safety (humor) helps to reduce stress; it provides relaxation to audience and relieves anxiety and everyday pressures. Moreover, philosophers endorse that the relationship of humor is connected with arousal. ${ }^{1}$ In addition to that, Rothbart suggested that audience laugh when arousal is at its peak but at the very same moment assesses the inducement as safe. To summarize it, arousal safety consists of the assessment by the target market with regard to humorous programs/ads

\footnotetext{
* Irfan Hameed, Ph.D. Chairperson, Department of Marketing \& Registrar, Iqra University

${ }^{* * *}$ Bibi Zainab, Ph.D. Student, Institute of Business Management

*** Syed Jazib Shamim, M.Phil. Student, University of Karachi

${ }^{1}$ Spotts, Harlan E., Marc G. Weinberger, and Amy L. Parsons. "Assessing The Use And Impact Of Humor On

Advertising Effectiveness: A Contingency Approach". Journal of Advertising 26, no. 3 (1997): 17-32.
} 
and it makes you feel relaxed and relieved from stresses which are surrounding the target market. $^{2}$

Humor appeal in TVCs is a prevalent issue in the field of research. Modern research prescribed that the humor appeal in advertisement is physiologically befitting to the target audience to get relieved from tension, nervousness and apprehension. ${ }^{3}$ It has been pragmatic that lighter mood increases and improves the recall of a TV commercial, and encouraging responses are generated from the target market, which results in positive behavior towards an advertisement ${ }^{4}$. Cline and Kellaris found that if humor in message execution is relevant to the advertisement style, this enhances the recall of such advertisement, particularly when rigorous need of such humor is evident. ${ }^{5}$

This study primarily focuses on the effects of Arousal Safety (Humor) on consumers purchase intention and the role of moderating variables like self-monitoring and message arguments. In order to make the relationship more pronounced certain moderating variables have also been used.

\section{Theoretical Background}

Humor is perceived similarly all over the globe ${ }^{6}$ that is why it's evident that from the ages of Philosophers like Aristotle, fun has premeditated its impact on individuals ${ }^{7}$. Over the period of hundred years researchers have studied the impact of fun on consumer behavior, but this subject is still having room to make more researches/ investigations about its impact on consumer behavior. Moreover, no such study has been made till date to explain the effect of Arousal Safety and considered as the best to prove the effect of fun on target market. ${ }^{8}$

Though researchers could not find the best and the final theory to prove the effect of fun on consumers, but humor is still been used as a contrivance to persuade or influence the consumers. ${ }^{9}$

Researchers like Speck found that humor appeal outstrip the other execution styles of advertisement as far as attention gathering is concerned and Eisend explained that humor ads provoke a positive reactions for the ads played on TV, provocation of a Positive

\footnotetext{
${ }^{2}$ Hsieh, C., Hsu, Y., \& Fang, W. “The Relationship between Deceptive Claims and Ad Effect: The Moderating Role of Humorous Ads". International Journal of Business and Information, 5 no. 1(2001): 1-25

${ }^{3}$ Szabo, Attila. "The Acute Effects Of Humor And Exercise On Mood And Anxiety". Journal of Leisure Research 35, no. 2 (2003): 152-162

${ }^{4}$ Mathur, Mahima, and AmitavaChattopadhyay. "The Impact Of Moods Generated By Television Programs On Responses To Advertising". Psychology and Marketing 8, no. 1 (1991): 59-77

${ }^{5}$ Hameed.I., Siddiqui, S. J., \& Husain, J. "Disparagement as a Processing Stimulus for Humor in Advertising".IBT Journal of Business Studies, 11 no.1 (2015), 75-88

${ }^{6} \mathrm{Nevo}$, Ofra, Baruch Nevo, and Janie Leong Siew Yin."Singaporean Humor: A Cross-Cultural, Cross-Gender Comparison". The Journal of General Psychology 128, no. 2 (2001): 143-156

${ }^{7}$ Vearch Thomas C. "A Theory Of Humor". Humor - International Journal of Humor Research 11, no. 2 (1998)

${ }^{8}$ Goldberg, Marvin E., and Gerald J. Gorn. "Happy And Sad TV Programs: How They Affect Reactions To Commercials". Journal of Consumer Research 14, no. 3 (1987): 387

${ }^{9}$ Duncan, Calvin P. "Humor In Advertising: A Behavioral Perspective". Journal of the Academy of Marketing Science 7, no. 4 (1979): 285-306
} 
reaction may lead towards increment in the positive buying behavior. In this age of globalization when local brand are competing with global brands, marketers are planning the international communication in such a way that they are synced with the culture of a specific country. ${ }^{10}$

However researches have been done, when marketer is going across the culture but the perspective of fun with reference to the cross culture management is still to be studied.

That is why advertisers still lack in the understanding of tools, techniques and types of humor to be more effective for different sort of cultures, while keeping in mind the defiance towards advertisement and intensions towards the purchasing behavior. ${ }^{11}$ Since this constraint of understanding exists, so this study has been made to examine the usefulness of humor tools to be used on different consumers possessing different motivational factors while the development of a TV commercial. ${ }^{12}$

\section{Humor in advertisements}

The main task of any ad campaign is to grab the attention and be more entertaining, and provide a reason to believe for the target market and brand itself ${ }^{13}$. That is why audience can never miss on to any advertisement which is having humor element in it; humor ads are more entertaining that is why they grab the audience attention. ${ }^{14}$ Humor appeal in not just been used in the Television advertisement but it is also been used on other mediums of promotion to gather the attention. Eisend proved in his study on humor that humor grabs the attention of target market which leads towards the positive responses in-terms of purchase.

Humor can be inferred from the process called arousal-safety. Arousal can be experienced to at its peak when consumers feel fear, joy or something related to these two. ${ }^{15}$ Source can be determined as humorous if it is not hazardous. Speck has taken American Association of Retired People (AARP) as an example in which an agent who was apparently scary for different people was actually helping them so this was gratifying the arousal safety process.

Viewers experience fun when they find the state of anxiety or uncertainty for safety and comfort for themselves or their surroundings. Thy feel relaxed when they experience that state of anxiety is safe or opposite results are inconsequential ${ }^{16}$. The message

\footnotetext{
${ }^{10}$ McGhee, Paul E. "Cognitive Development And Children's Comprehension Of Humor". Child Development 42, no. 1 (1971): 123

${ }^{11}$ Apte, Mahadev L. Humor And Laughter. Ithaca (New York: Cornell University Press, 1985)

${ }^{12}$ Kamins, Michael A., Lawrence J. Marks, and Deborah Skinner. "Television Commercial Evaluation In The Context Of Program Induced Mood: Congruency Versus Consistency Effects". Journal of Advertising 20, no. 2 (1991): 1-14

${ }^{13}$ Pieters, R., Warlop, L., \& Wedel, M. "Breaking through the clutter: Benefits of advertisement originality and familiarity for brand attention and memory". Management Science, 48, no.6 (2002), 765 - 781

${ }^{14}$ Gulas, Charles S, and Marc G Weinberger. Humor In Advertising. Armonk, (New York: Sharpe, 2006)

15 Ibid.

${ }^{16}$ Ibid.
} 
communicates or triggers the doubts in-terms of apprehensions. ${ }^{17}$ Speck $^{18}$ enlightened that arousal safety inculcate and deluge positivity such as warm, cute, friendly or familiar. At its peak it companionate a strong bounding with the one who closely missed disasters. In arousal safety there is always apprehensions and nervousness as the psyche of any individual.

Moreover, arousal-safety includes how audiences find humor in any topic and how that topic relaxes them from nervousness and apprehensions. Discomforting presence, behavior, intention, or fate of another person, affective uncertainty, play signal, and safety judgment are the pre-requisites of arousal for arousal safety, most of the time its effect is positive.

\section{Relatedness of Humor in Advertising}

Effect of humor in advertisement is highly dependent upon the humor element to the message element. Relatedness or relevance in advertising is designated to both humor appeal and the non-humor appeal advertisement campaigns. ${ }^{19}$

A research conducted by Madden and Weinberger proved that near about the $88 \%$ advertisers think that the humor must have a link to product shown in the advertisement. According to Speck there are three levels of humor which classify relatedness of any advertisement; e.g., Intentional Relatedness, Structural Relatedness, and Thematic Relatedness.

\section{Intentional Relatedness}

Audience behavior is been controlled and shaped by the arrangement of humor that is contemporary when the advertisement message is internationally labeled with the product benefits, brand name, product image and competitor weaknesses. ${ }^{20}$

A message is internationally linked with humor when the message strategy is prescribed and treated as information; the level of humor domination in ad campaigns is recognized as Intentional relatedness of advertisement. ${ }^{21}$

Concluding the debate, arousal philosophy is been implemented to help audience release the nervousness and apprehensions, it's evident that people feel amused by all those topics which are uncertain in such a way that they could release their strains and pressures. ${ }^{22}$

\footnotetext{
${ }^{17}$ Ibid.

${ }^{18}$ Speck, P. S. "On Humor And Humor In Advertising". PhD, Texas Tech University, 1987.

${ }^{19}$ Beard, Fred K. Humor In The Advertising Business. (Lanham: Rowman\& Littlefield, 2008).

${ }^{20}$ Sternthal, B., \& Craig, C. S. "Humor in advertising”.Journal of Marketing 37 (1973), 12 - 18.

${ }^{21}$ Weinberger, Marc G., and Charles S. Gulas. "The Impact Of Humor In Advertising: A Review". Journal of Advertising 21, no. 4 (1992): 35-59.

${ }^{22}$ Gulas, Charles $\mathrm{S}$ op.cit.
} 


\section{Effects of Humor}

People like funny advertisements ${ }^{23}$. A number of research papers are available on the role of humor in advertising ${ }^{24}$ but a clear difference was not observed/reported in most of the studies between humorous and non-humorous advertisements. Hence the results present contrasting picture in terms of humor usage in today'sadvertisements. ${ }^{25}$ The advertisements have many elements like shock, violence and humor as wellto capture attention of the audience and positively affect recall and attitudes. ${ }^{26}$

\section{H1: Arousal Safety in advertisements has significantly positive impact on consumer's Purchase Intention.}

\section{Interaction of Self-Monitoring}

The environment also forces individuals to behave in certain ways. ${ }^{27}$ The people who behave in certain ways especially because others are noticing their behavior are high in self-monitoring. Arousal safety in the advertisement shows a feeling of liveliness and high self-monitors are concerned about their image at the same time. The high selfmonitors respond favorably to the humorous (Arousal Safety) advertisements. ${ }^{28}$

$\mathrm{H}_{2}$ : Self-Monitoring moderates the positive relationship between Arousal Safety and consumer's Purchase Intention, such that a person high in selfmonitoring is more inclined towards purchase intention and vice versa.

\section{Indirect effect through Attitude towards the Advertisement}

The arousal safety in the advertisement evokes a feeling of understanding and gives a feeling of joy. ${ }^{29}$ Ultimately the people develop a favorable attitude towards the advertisement as they start to like the advertisement. ${ }^{30}$ The advertisements likeability is the major factor that forces any consumer to make a purchase decision in favor of the advertised brand. ${ }^{31}$

\footnotetext{
${ }^{23}$ WoltmanElpers, Josephine L. C. M., Ashesh Mukherjee, and Wayne D. Hoyer. "Humor In Television Advertising: A Moment-To-Moment Analysis". Journal of Consumer Research 31, no. 3 (2004): 592-598.

${ }^{24}$ Gelb, B. D., \&Zinkhan, G. M. (1986).Humor and advertising effectiveness after repeated exposures to a radio commercial.Journal of Advertising, 15(2), 15-20, 34.

${ }^{25}$ Friese, Malte, Michaela Wänke, and Henning Plessner. "Implicit Consumer Preferences And Their Influence On Product Choice". Psychology and Marketing 23, no. 9 (2006): 727-740.

${ }^{26}$ Speck, P. S. "On Humor And Humor In Advertising". PhD, (Texas: Texas Tech. University, 1987)

${ }^{27}$ Gulas, Charles S, op.cit.

${ }^{28}$ Lammers, H.Bruce, Laura Leibowitz, George Edw. Seymour, and Judith E. Hennessey. "Humor And Cognitive Responses To Advertising Stimuli: A Trace Consolidation Approach". Journal of Business Research 11, no. 2 (1983): 173-185.

${ }^{29}$ Cline, Thomas W., and James J. Kellaris. "The Influence Of Humor Strength And Humor-Message Relatedness On Ad Memorability: A Dual Process Model". Journal of Advertising 36, no. 1 (2007): 55-67.

${ }^{30}$ MacKenzie, S. B., \& Lutz, R. J. (1989).An empirical examination of the structural antecedents of attitude toward the ad in an advertising pretesting context.Journal of Marketing, 53, 48-56.

${ }^{31}$ Burke, Raymond R., and Thomas K. Srull. "Competitive Interference And Consumer Memory For Advertising". Journal of Consumer Research 15, no. 1 (1988): 55-68.
} 


\section{H3: Attitude towards the advertisement mediates the positive relationship between Arousal Safety and consumer's Purchase Intention.}

\section{Mediating Role of Attitude towards the Brand}

The attitude of the consumer towards the advertisement if found favorable then a consumer might go to purchase a product, but the idea of considering the attitude towards the brand is not contradicting. ${ }^{32}$ So the series of mediating variables should be used to find the effect of arousal safety in advertisement. ${ }^{33}$ The attitude towards the brand should also be positive in order to have favorable reaction from consumer. ${ }^{34}$ This led us to multimediated model.

H4: The relationship between Attitude towards the advertisement and Purchase Intention is mediated positively by Attitude towards the brand, when humor type Arousal Safety is used as predictor of attitude towards the advertisement.

\section{Moderating Role of Message Arguments}

The main purpose of the advertisement is to communicate the relevant information to the audience and the question arises that whether the same message has been communicated or not. ${ }^{35}$ The information given in the advertisement also attracts the consumers and they should be able to recall relevant information as and when required so. ${ }^{36}$

H5: The positive association of Arousal Safety with consumer's Purchase Intention is strengthened by message argument, such that compelling message argument moderates the association positively and vice versa.

Figure 1: Hypothesized Model

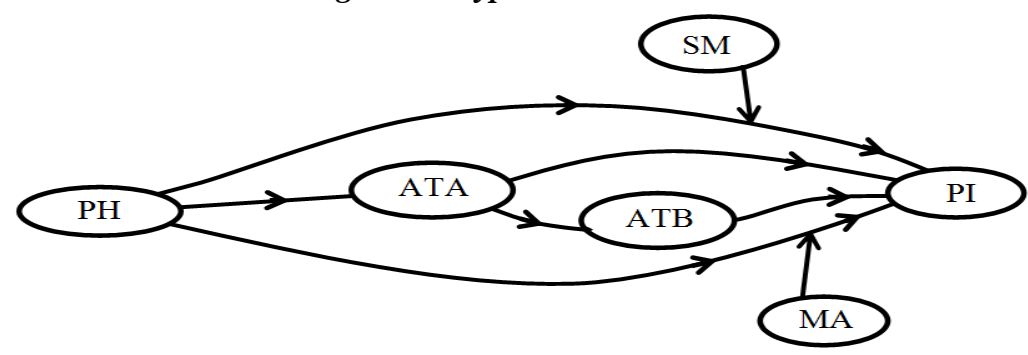

\footnotetext{
${ }^{32}$ Eisend, Martin, and FaridTarrahi. "The Effectiveness Of Advertising: A Meta-Meta-Analysis Of Advertising Inputs And Outcomes". Journal of Advertising 45, no. 4 (2016): 519-531.

${ }^{33}$ WoltmanElpers, Josephine L. C. M., Ashesh Mukherjee, and Wayne D. Hoyer. "Humor In Television Advertising: A Moment-To-Moment Analysis". Journal of Consumer Research 31, no. 3 (2004): 592-598.

${ }^{34}$ Batra, Rajeev, and Michael L Ray. How Advertising Works At Contact. (Stanford, California.: Graduate School of Business, Stanford University, 1983)

${ }^{35}$ Petty, R. E., \&Cacioppo, J. T. (1981).Attitudes and Persuasion: Classic and Contemporary Approaches. Dubuque, IA: William C. Brown.

${ }_{36}^{36}$ Ibid.
} 


\section{Research Methodology Method of Data Collection}

A self-administered questionnaire has been used to collect the data from the targeted representatives of the population. The questionnaire was given to respondents in a setting where environment could be controlled well in order to get to know their observation about the particular advertisement. Two different advertisements were carefully selected making sure that there is an aspect of Arousal Safety (Humor) in the preferred advertisement. Then it was made sure that the selected advertisements have the aspect of humor by showing to three different faculty members of a university in different settings. A questionnaire was developed for all of the variables (dependent, independent, moderating and mediating).

\section{Sampling Technique \& Sample Size}

The sample selection in fact was the most difficult part of the study because the nature of the study says that only that part of the population can be selected which can give their responses after reading and observing. The study also required a large number of respondents should be sitting at one place so that advertisementscould be shown to them. So a total of 206 university students have been targeted during their classes for the purpose of data collection.

\section{Instrument of Data Collection}

Self-administered close ended questionnaire based on scale presented by RensisLikert (known as Likert scale) another name given to same scale is summative rating scale and semantic differential scaling was also used to gather data. Moderating variable selfmonitoring was based on likert scale and the questions of all other variables were based on semantic differential scaling. The respondents had to answer on a seven point scale where 1 being strongly disagree and 7 being strongly agree. The established scales have been used to measure unobserved variables. In order to study humor and purchase intention the scale developed by Zhang $(1996)^{37}$ was used with $\alpha=0.91$ and 0.89 . The modified scale of self-monitoring was adopted from the study of Lennox and Wolfe (1984).$^{38}$ The scale for attitude towards the brand and attitude towards the advertisement has been adopted from Cho and Stout $(1993)^{39}$ with reliability of 0.84 and 0.87 . The scale for message arguments have been adopted from the study of Andrews and Shimp (1990) with $\alpha=.85$.

\footnotetext{
${ }^{37}$ Zhang, Yong. "The Effect Of Humor In Advertising: An Individual-Difference Perspective". Psychology and Marketing 13, no. 6 (1996): 531-545.

${ }^{38}$ Lennox, Richard D., and Raymond N. Wolfe. "Revision Of The Self-Monitoring Scale.". Journal of Personality and Social Psychology 46, no. 6 (1984): 1349-1364.

${ }^{39}$ Cho, H. G., \& Stout, P. A. "An extended perspective on the role of emotion in advertising processing”.Advances in Consumer Research, 20 (1990): 692-697.
} 


\section{Statistical Test}

Initial test was to find out the missing values in the data, built in module in SPSS that is "Transform $\rightarrow$ Replace missing values" have been used and only few missing values have been found so they were covered using mean values.

The next issue with most of the respondents is that they don't give responses within given options. In this research the questions were on 7-point scale. When a respondent answers any other value than given in research instrument or if there is any error on the part of data entry is known as "Aberrant". To find out this error graphical representation through box plot has been done, this test revealed that there are no aberrant values. Aberrant values can also be traced through the analysis of maximum and minimum values of each variable. When the aim is to use Multivariate analysis then normality test is applied, Graphical analysis and application of statistical methods on each variable or item is to be used to test normality for grouped data, but the issue arises when to test ungrouped data so for that reason only statistical tests are useful enough.

Kolmogorov-Smirnov and Shapiro-Wilk tests of normality have been applied, the values Shapiro-Wilk tests of normality was of no use in this study because for that test the data should be less than 50. So the values of Kolmogorov-Smirnov test showed that it differs from normal distribution so the values of all variables were between the range +1.5 to 1.5 except one item and value of Kurtosis for eight items were outside +1.5 to -1.5 . The outlier's detection became important in this case, for that reason Mahalanobis distance measuring method was used (Table-1).

Table 1: Multivariate outliers

\begin{tabular}{|r|r|c|c|}
\hline \multicolumn{1}{l|}{ Sr. } & \multicolumn{1}{|l|}{ Case ID } & Mahalanobis Distance & Probability \\
\hline 1 & 157 & 105.30591 & .0000 \\
\hline 2 & 51 & 94.28985 & .0000 \\
\hline 3 & 23 & 88.48786 & .0000 \\
\hline 4 & 40 & 78.52302 & .0002 \\
\hline 5 & 144 & 76.40209 & .0003 \\
\hline 6 & 88 & 75.23855 & .0004 \\
\hline 7 & 103 & 73.99502 & .0006 \\
\hline 8 & 19 & 72.47817 & .0009 \\
\hline
\end{tabular}

After removing outliers the analysis of skewness and kurtosis value revealed that kurtosis value of 08 items are still outside the range of +1.5 and -1.5 . There was no significant improvement in the data after removing these outliers so they were not removed and all of the items were used for further analyses.

The data has been cleaned up and now it's the time for further analysis, so CFA (Confirmatory Factor Analysis) has been applied using Structural equation modelling in 
Amos 18. The reason for using AMOS is that SPSS don't have CFA; SPSS can be used to apply EFA (Exploratory Factor Analysis). CFA is applied for four variables because scales are well established and have good reliability in previous studies.

Various fit indices have been reported but four key fit indices following the recommendations of Schreiber, Stage, King, Nora, \& Barlow ${ }^{40}$ which are CMIN/df, CFI, TLI, and RMSEA indices have been used in this study because same indices have been used in similar studies.

CFA results have been analyzed in detail and it has been concluded that there is the issue of multicollinearity in the data so collinearity diagnostics was also applied to data, which showed that VIF and Tolerance are below the threshold value, so multicollinearity is not a thing to ponder upon. Multicollinearity has been assessed by Tolerance, and Variance inflation factor (VIF) and then reliability has been tested. After the application of preliminary tests the cleaned up data has been used for hypotheses testing.

\section{CFA for Status Evaluations}

The results of initial CFA (model 1) showed bad fit to data. While checking the factor loadings of all the items, it was observed that one item of attitude towards brand (i.e ATB_3) had factor loadings below .4. So following the recommendations of Kline ${ }^{41}$, the item with factor loading below the minimum threshold of .5 was removed from the CFA model. Further, review of modification indices revealed that two error terms of attitude towards the advertisement scale had high shared covariance so a covariance was drawn between these error terms. After the necessary changes, CFA model 2 was conducted which demonstrated a good fit to data.

Table 2: Fit indices of CFA for Four Key variables

\begin{tabular}{|l|l|l|l|l|}
\hline Model & RMSEA & TLI & CFI & CMIN/df \\
\hline Model 1: Four factor model with all items & .060 & .87 & .89 & 1.74 \\
\hline Model 2: Four factor model with some changes & .057 & .91 & .92 & 1.67 \\
\hline
\end{tabular}

\footnotetext{
${ }^{40}$ Schreiber, J. B., Stage, F. K., King, J., Nora, A., \& Barlow, E. A. "Reporting Structural Equation Modeling and Confirmatory Factor Analysis Results: A Review". The Journal of Educational Research, 99 no. 6 (2006), 323-337.

${ }^{41}$ Kline, R. B. Principles And Practice Of Structural Equation Modeling. 3rd ed. (New York: The Guilford Press., 2011)
} 
Figure 2: Factor Loadings

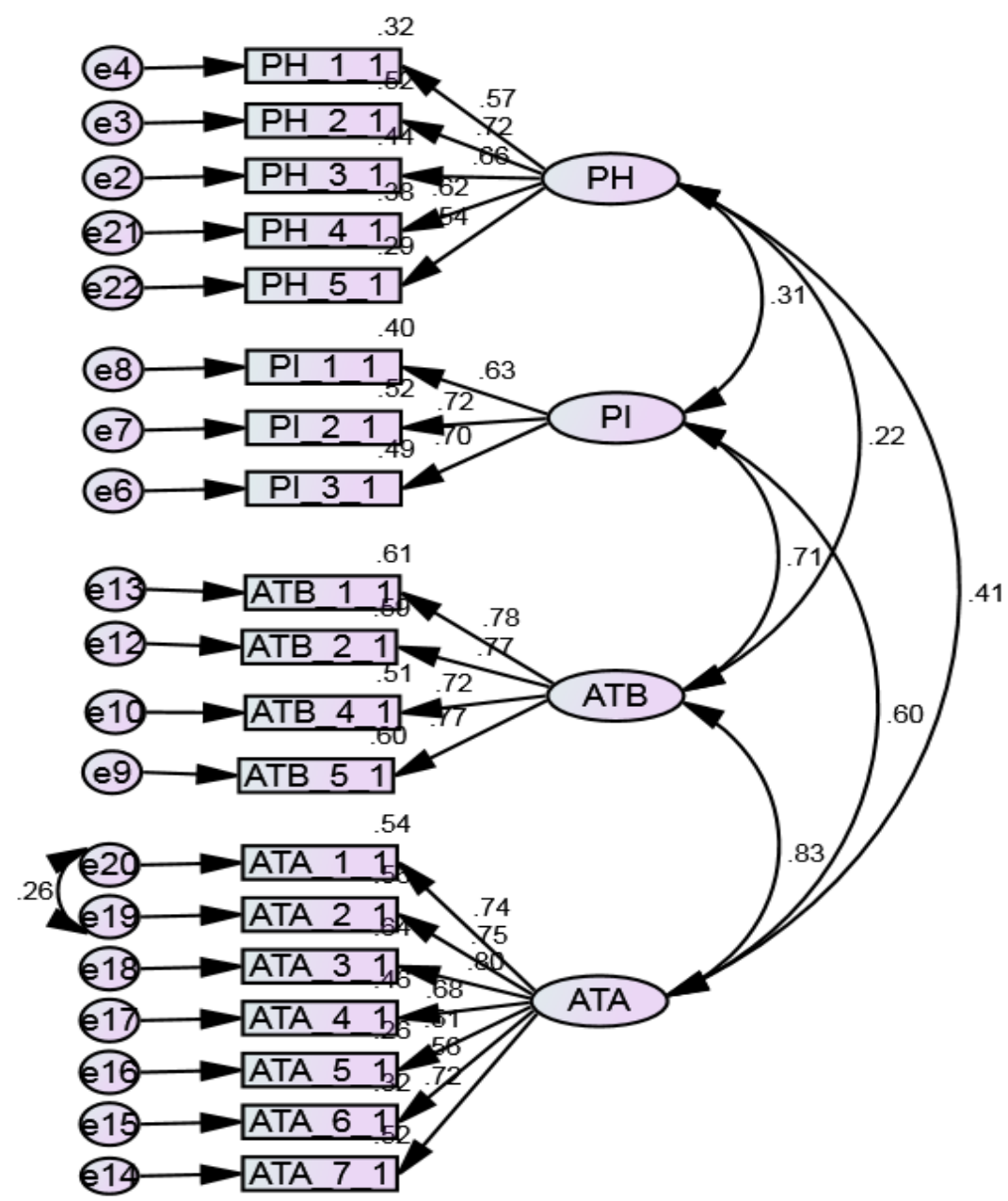

The detailed analysis of the above CFA figure revealed that the two constructs i.e. ATA and ATB showed very strong correlation $(\mathrm{r}=.83)$, which creates the concerns of multicolinearity. For this purpose we ran the collinearity diagnostics using SPSS. The results of collinearity diagnostics are presented in the table below, which revealed that the values of VIF and Tolerance are below the threshold values, which revealed that mulicolinearity is not a major issue in our data set. 
Table 3: Colinearity diagnostics

\begin{tabular}{|l|l|l|l|}
\hline \multicolumn{2}{|l|}{ Model } & Collinearity Statistics \\
\cline { 3 - 4 } & & Tolerance & VIF \\
\hline \multirow{3}{*}{1} & $($ Constant $)$ & & \\
\cline { 2 - 4 } & ATA & .523 & 1.911 \\
\cline { 2 - 4 } & ATB & .523 & 1.911 \\
\hline \multirow{4}{*}{2} & (Constant) & & \\
\cline { 2 - 4 } & ATA & .481 & 2.079 \\
\cline { 2 - 4 } & ATB & .521 & 1.918 \\
\cline { 2 - 4 } & PH & .887 & 1.127 \\
\hline
\end{tabular}

a. Dependent Variable: PI

Then we further checked the reliability of the constructs, and it was observed that all the four constructs have reliability value greater than the threshold value of .7.

Both model 1 and model 2 showed poor fit to data but model 2 had relatively good fit to data. So we kept the model 2 and made further changes to it. We removed the items of low factor loading of SM and only 5-items remained which had significant factor loading and they mainly represented the dimension of ability to modify the self-representation. The model 3 showed excellent fit to the data.

Table 4: Fit indices of CFA for Moderators

\begin{tabular}{|l|l|l|l|l|}
\hline Model & RMSEA & TLI & CFI & CMIN/df \\
\hline $\begin{array}{l}\text { Model 1: Moderators (with two } \\
\text { dimensions of SM) }\end{array}$ & .150 & .78 & .68 & 4.54 \\
\hline $\begin{array}{l}\text { Model 2: Moderators (by combining } \\
\text { the SM dimensions) }\end{array}$ & .042 & .87 & .88 & 1.37 \\
\hline $\begin{array}{l}\text { Model 3: Moderator (SM single } \\
\text { dimension after removing items) }\end{array}$ & .025 & .98 & .99 & 1.13 \\
\hline
\end{tabular}


Figure 3: Factor loadings for moderators

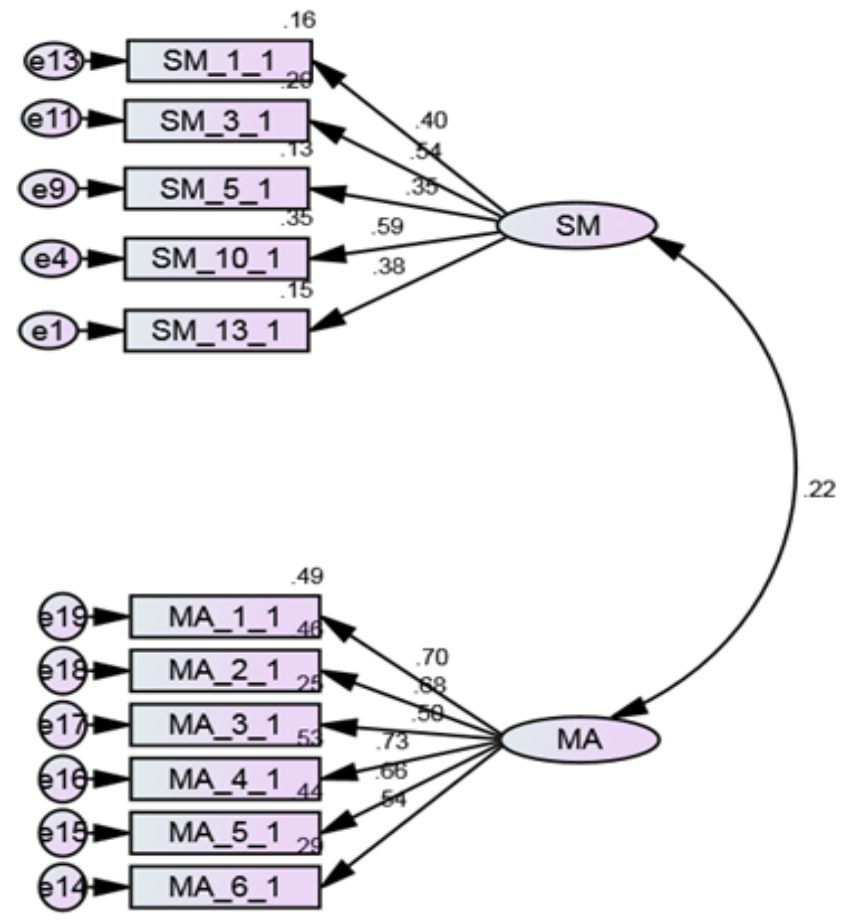

Table 5: Descriptive statistics and Correlations

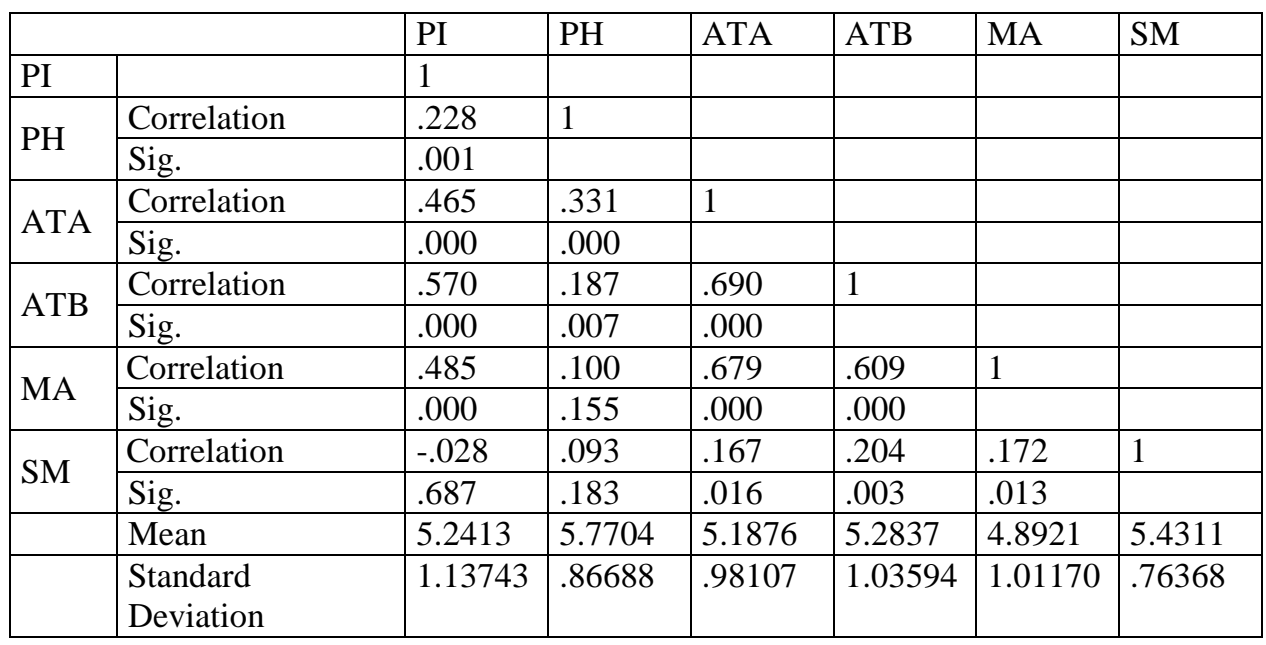


The detailed review of the above table revealed that all the studied variables have significant correlation with each other except in few cases. The insignificant correlations were observed between MA and PH, SM and PI, and SM and PH.

\section{Hypotheses Testing}

We used multiple regressions to test our hypotheses. We build separate regression models for testing our hypotheses as the model involves two mediators and two moderators.

Testing Hypothesis 1: The results of the regression analysis revealed that Arousal safety significantly predicted purchase intentions $(\beta=.228, p<.01)$. Hence our hypothesis was supported by the data.

Table 6: Coefficients ${ }^{a}$

\begin{tabular}{|l|l|l|l|l|l|l|}
\hline \multirow{2}{*}{\begin{tabular}{l} 
Model \\
\cline { 3 - 7 }
\end{tabular}} & \multicolumn{2}{|l|}{$\begin{array}{l}\text { Unstandardized } \\
\text { Coefficients }\end{array}$} & $\begin{array}{l}\text { Standardized } \\
\text { Coefficients }\end{array}$ & \multirow{2}{*}{$\mathrm{t}$} & \multirow{2}{*}{ Sig. } \\
\cline { 3 - 8 } & $\mathrm{B}$ & Std. Error & Beta & & .000 \\
\hline \multirow{2}{*}{1} & (Constant) & 3.515 & .522 & & 6.734 & .001 \\
\cline { 2 - 7 } & PH & .299 & .089 & .228 & 3.345 & .001 \\
\hline
\end{tabular}

a. Dependent Variable: PI

Testing Hypothesis 2:The results of the analysis shown in the table below highlighted that SM significantly moderated the relationship between PH and PI as the effect of interaction term was found to be significant (Unstandardized $\beta=.2595, p<.01$ ). The effect of moderation in this analysis is categorized as pure moderation as the moderator variable (i.e. SM) itself has non-significant effect on the dependent variable.

Table 7: Modprobe

\begin{tabular}{|l|l|l|l|l|}
\hline Variable & B & SE & t statistic & Significance (p) \\
\hline Constant & 5.2254 & .0765 & 68.3215 & .000 \\
\hline PH & .3489 & .0900 & 3.8762 & .001 \\
\hline SM & -.0786 & .1005 & -.7820 & .435 \\
\hline Interact (PHxSM) & .2595 & .0957 & 2.7098 & .007 \\
\hline
\end{tabular}

For further probing the interaction effect we developed the graph of the moderation effect. The graph below clearly shows that two lines are interacting and crossing each other, which highlights that when $\mathrm{PH}$ is low but the person is high in self-monitoring then the PI will be high. And if advertisement is high in PH but the SM is low, then the PI will also be lower. 


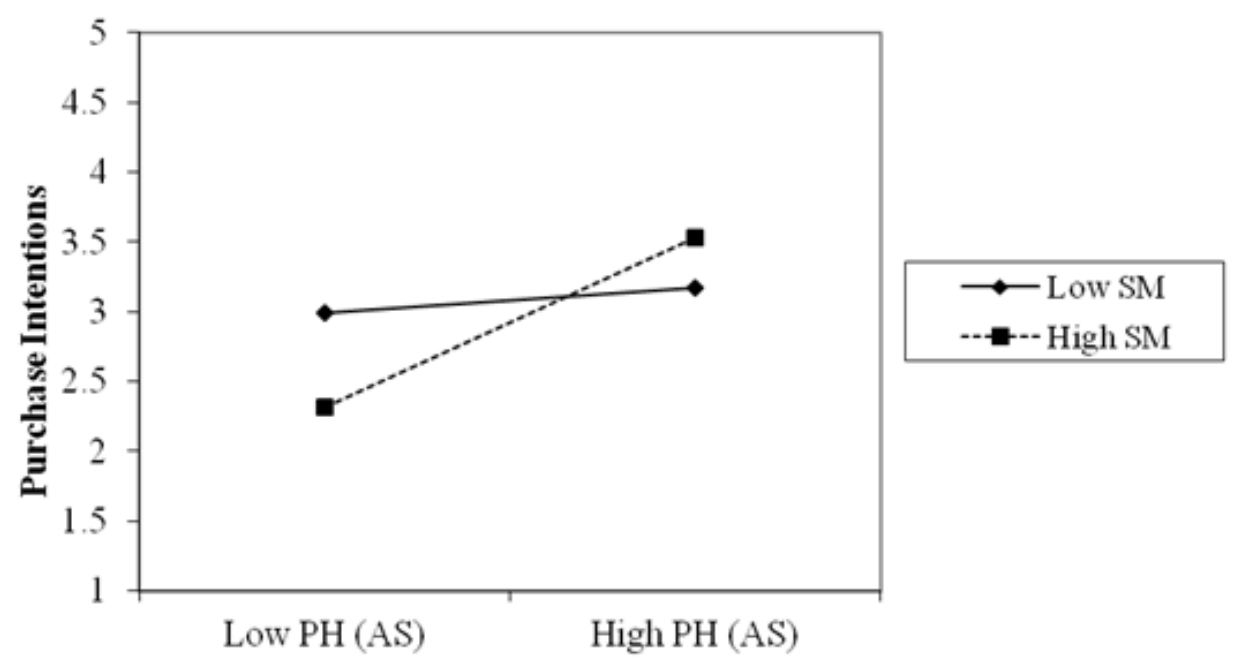

Figure 4: Moderation results

4.3 Testing Hypothesis 3: The results shown in table below highlighted that both a (Unstandardized $\beta=.3745, p<.001$ ) and $\mathrm{b}$ (Unstandardized $\beta=.5068, p<.001$ ) path are significant and also the indirect effect of independent variable (through mediator) is also significant which supports our hypothesis. Further if we look at the direct effect (c prime) which is insignificant (Unstandardized $\beta=.1094, p>.05$ ), highlighting a fully mediated relationship.

Table 8: Indirect

\begin{tabular}{|l|l|l|l|l|l|}
\hline Relationship & $\begin{array}{l}\text { Unstandardized } \\
\text { effect }\end{array}$ & $\mathrm{SE}$ & $\mathrm{t}$ & $\mathrm{Z}$ & $P$ \\
\hline PH->ATA (a path) & .3745 & .0748 & 5.0084 & -- & .000 \\
\hline ATA->PI (b path) & .5068 & .0761 & 6.6640 & -- & .000 \\
\hline Total effect (c path) & .2992 & .0894 & 3.3454 & -- & .001 \\
\hline Direct effect (c prime) & .1094 & .0861 & 1.2714 & -- & .205 \\
\hline $\begin{array}{l}\text { Indirect effect } \\
\text { (through mediator) }\end{array}$ & .1898 & .0472 & -- & 4.0171 & .001 \\
\hline
\end{tabular}

4.4 Testing Hypothesis 4: The results revealed that ATB fully mediated the relationship between ATA and PI as the indirect effect was significant (Unstandardized $\beta=.3815, p$ $<.001)$. Hence the hypothesis was supported. 


\section{Table 9: Indirect}

\begin{tabular}{|l|l|l|l|l|l|}
\hline Relationship & Unstandardized effect & SE & T & $\mathrm{z}$ & $p$ \\
\hline ATA->ATB (a path) & .7290 & .0535 & 13.6318 & -- & .000 \\
\hline ATB->PI (b path) & .5232 & .0869 & 6.0224 & -- & .000 \\
\hline Total effect (c path) & .5388 & .0719 & 7.4964 & -- & .000 \\
\hline Direct effect (c prime) & .1573 & .0917 & 1.7150 & -- & .088 \\
\hline $\begin{array}{l}\text { Indirect effect (through } \\
\text { mediator) }\end{array}$ & .3815 & .0689 & -- & 5.5336 & .000 \\
\hline
\end{tabular}

4.5 Testing Hypothesis 5: The results highlighted that MA does not work as a moderator on the relationship between PH and PI. Instead MA has a strong impact on PI so it can be proposed as a focal predictor of purchase intention alongside PH. Our hypothesis 5 was not supported by the results of the analysis.

Table 10: Modprobe

\begin{tabular}{|c|c|c|c|c|}
\hline Variable & B & SE & $\mathrm{t}$ statistic & $\begin{array}{l}\text { Significance } \\
\text { (p) }\end{array}$ \\
\hline Constant & 5.2412 & .0686 & 76.3584 & .000 \\
\hline PH & .2379 & .0878 & 2.7111 & .007 \\
\hline MA & .5252 & .0685 & 7.6718 & .000 \\
\hline $\begin{array}{l}\text { Interact } \\
\text { (PHxMA) }\end{array}$ & .0006 & .0781 & .0082 & .994 \\
\hline
\end{tabular}

The model consisted of one independent variable that is Arousal Safety referred to as $\mathrm{PH}$ and dependent variable Purchase Intention denoted by PI, Attitude Towards the Advertisement by ATA, Attitude Towards the Brand by ATB, Self-monitoring by SM, and Message Arguments as MA.

\section{Conclusion \\ Discussions}

The research done in this dissertation is unique in a sense that this association between the variables has never been studied before. Many researchers have done research by using need for cognition as moderating variable, identifying it as a major psychographic variable. There are three Psychographic variables as explained by various researchers, like need for cognition, self-monitoring, and political ideology. Political ideology has never been used as a variable in the study of humor. Zhang ${ }^{42}$ used need for cognition as moderating variable between humor and purchase intention, but he haven't identified the types of humor nor used any of them in his any research paper. Same is the case for other researchers in the same field as they studied the effect of need for cognition and some also highlighted the importance of self-monitoring.

${ }^{42}$ Zhang, Yong. Op.cit 
The relationship of Arousal Safety(humor) with purchase intention was discussed for the first time and then the psychographic variables as mentioned in various research papers have been incorporated. As the humor plays a vital role in shaping the purchase intention of an individual but it has a different effect on individuals of different psychographic states. Hence the psychographic state of self-monitoring has been selected very carefully and it was highly suitable.

Many researchers have done research in a setting where a number of respondents sit together for giving responses on a questionnaire. The idea of showing advertisement first and then collecting their responses in setting where many respondents are gathered together also highlights the fact that they notice others as well and enjoy the humor in the advertisement. Noticing the behavior of others and modifying once own behavior falls under the heading of self-monitoring. The people high in self-monitoring have shown more favorable response in exposure to the humorous advertisement. Talking about the uniqueness of the research some mediated variables have been used. Using two different humors advertisements one by one with the attitude towards the advertisement and attitude towards the brand is itself a different association than any of the existing research under the domain of Arousal Safety (humor) in advertising.

Multi-Mediation has not been used in many of the existing research papers especially related to humor but this research stated the multi-mediated model. In this way the hypothesis stated four variables in one row, which are Arousal Safety, attitude towards the advertisement and attitude towards the brand and purchase intention. In addition to these associations message argument was also used as a moderating variable. The research proved that the relationship between the Arousal Safety and Purchase Intention is positive even when moderating and mediating variables were used; there was no relationship only when the moderating variable was message arguments.

\section{Managerial Implications}

The research on advertising has prime importance especially in this age of mass marketing where companies are stuck in the advertising clutter. As per an estimate out of the 60 minutes program on a television channel 25 minutes are being taken by the advertisements. Where the companies are airing the advertisements again and again in order to make it memorable for the audience. People only remember the advertisements which are unique and different from the majority of advertisements. Now a day's advertising agencies are joining hands with the entertainment giants in order to create entertaining advertisements.

The same happened in United States with the intersection of Maddison and Vine. Maddison Avenue where there are offices of advertising agencies and there is a crosssection of Vine Street where there is Hollywood. With the intersection of both of them the advertisements became more entertaining and the advertising industries of India and Pakistan are somewhat the reflection of the Hollywood. Humor has also become an important part of the advertisements where companies tell you the features and ultimately convince you to purchase a particular product. There is no as such research published reflecting the Pakistan economy and the responses of Pakistani consumers. The idea of 
using three types of humor as independent variable makes this study stand out from others. In this way it gives the results that what are different types of humorous advertisements and how they affect the consumer's perception about the product. The findings of this research are useful for the media agencies and most of the companies who are trying to create the advertisements worth memorable.

\section{Future Research}

The research is a never ending process; the research cycle keeps on moving in any case. So none of the research can be said as the final in a particular field. Obviously finding of this study can be used further as basis and even the vision and scope can be broadened. The research can be extended towards the use of the third psychographic variable i.e., political ideology. Political ideology has never been used before in any of the research related to humor in advertisements. The people with high political ideology can be considered as the people with high sense of critical thinking and taking out meanings and able to relate interrelated sequence of activities. It can be tested that the people who have high sense of political ideology will give a positive response towards purchase intention when exposed with the humorous advertisement.

This research was based on the video advertisements so research was strictly focused towards the television and the Medias where people can watch video of the advertisement and also are able to hear the voice of it. The research can be extended by using the print advertisements especially those given in newspapers. The advertisements which are being displayed on sign boards and bill boards they also need to be pondered upon. In order to make print advertisements more effective they need to be researched on the basis of types also incorporating the moderating and mediating variables.

\section{References}

Andrews, J. Craig, and Terence A. Shimp. "Effects Of Involvement, Argument Strength, And Source Characteristics On Central And Peripheral Processing Of Advertising". Psychology and Marketing7, no. 3 (1990): 195-214.

Apte, Mahadev L. Humor And Laughter. Ithaca (New York: Cornell University Press, 1985)

Batra, Rajeev, and Michael L Ray. How Advertising Works At Contact. Stanford, Calif.: Graduate School of Business, Stanford University, 1983.

Beard, Fred K. Humor In The Advertising Business. Lanham: Rowman\& Littlefield, 2008.

Burke, Raymond R., and Thomas K. Srull. "Competitive Interference and Consumer Memory For Advertising". Journal of Consumer Research 15, no. 1 (1988): 55.

Cho, H. G., \& Stout, P. A. "An extended perspective on the role of emotion in advertising processing”. Advances in Consumer Research, 20 (1990): 692-697. 
Cline, Thomas W., and James J. Kellaris. "The Influence Of Humor Strength And Humor-Message Relatedness On Ad Memorability: A Dual Process Model". Journal of Advertising 36, no. 1 (2007): 55-67.

Cline, Thomas W., Moses B. Altsech, and James J. Kellaris. "When Does Humor Enhance Or Inhibit Ad Responses? - The Moderating Role of The Need For Humor". Journal of Advertising 32, no. 3 (2003): 31-45.

Duncan, Calvin P. "Humor In Advertising: A Behavioral Perspective". Journal of the Academy of Marketing Science 7, no. 4 (1979): 285-306.

Eisend, Martin, and FaridTarrahi. "The Effectiveness Of Advertising: A Meta-MetaAnalysis Of Advertising Inputs And Outcomes". Journal of Advertising 45, no. 4 (2016): 519-531.

Friese, Malte, Michaela Wänke, and Henning Plessner. "Implicit Consumer Preferences And Their Influence On Product Choice". Psychology and Marketing 23, no. 9 (2006): 727-740.

Gelb, Betsy D., and George M. Zinkhan. "Humor And Advertising Effectiveness After Repeated Exposures To A Radio Commercial". Journal of Advertising 15, no. 2 (1986): 15-34.

Goldberg, Marvin E., and Gerald J. Gorn. "Happy And Sad TV Programs: How They Affect Reactions To Commercials". Journal of Consumer Research 14, no. 3 (1987): 387.

Gulas, Charles S, and Marc G Weinberger. Humor In Advertising. Armonk, (New York: Sharpe, 2006)

Hameed. I., Siddiqui, S. J., \& Husain, J. "Disparagement as a Processing Stimulus for Humor in Advertising". IBT Journal of Business Studies, 11 no.1 (2015), 75-88.

Kamins, Michael A., Lawrence J. Marks, and Deborah Skinner. "Television Commercial Evaluation In The Context Of Program Induced Mood: Congruency Versus Consistency Effects". Journal of Advertising 20, no. 2 (1991): 1-14.

Kline, R. B. Principles And Practice Of Structural Equation Modeling. 3rd ed. (New York: The Guilford Press., 2011).

Lammers, H.Bruce, Laura Leibowitz, George Edw. Seymour, and Judith E. Hennessey. "Humor And Cognitive Responses To Advertising Stimuli: A Trace Consolidation Approach". Journal of Business Research 11, no. 2 (1983): 173-185.

Lennox, Richard D., and Raymond N. Wolfe. "Revision Of The Self-Monitoring Scale.". Journal of Personality and Social Psychology 46, no. 6 (1984): 1349-1364. 
MacKenzie, Scott B., and Richard J. Lutz. "An Empirical Examination Of The Structural Antecedents Of Attitude Toward The Ad In An Advertising Pretesting Context". Journal of Marketing 53, no. 2 (1989): 48.

Flaherty, Karen, Marc G. Weinberger, and Charles S. Gulas. "The Impact Of Perceived Humor, Product Type, And Humor Style In Radio Advertising". Journal of Current Issues \& Research in Advertising 26, no. 1 (2004): 25-36.

Mathur, Mahima, and AmitavaChattopadhyay. "The Impact Of Moods Generated By Television Programs On Responses To Advertising". Psychology and Marketing 8, no. 1 (1991): 59-77.

McGhee, Paul E. "Cognitive Development And Children's Comprehension Of Humor". Child Development 42, no. 1 (1971): 123.

Nevo, Ofra, Baruch Nevo, and Janie Leong Siew Yin. "Singaporean Humor: A CrossCultural, Cross-Gender Comparison". The Journal of General Psychology 128, no. 2 (2001): 143-156.

Pieters, R., Warlop, L., \& Wedel, M. "Breaking through the clutter: Benefits of advertisement originality and familiarity for brand attention and memory". Management Science, 48, no.6 (2002), 765 - 781.

Rothbart, M. K. "Laughter in young children". Psychological Bulletin, 80 no. 3 (1973), 247-256.

Schreiber, J. B., Stage, F. K., King, J., Nora, A., \& Barlow, E. A. "Reporting Structural Equation Modeling and Confirmatory Factor Analysis Results: A Review". The Journal of Educational Research, 99 no. 6 (2006), 323-337.

Speck, P. S. "On Humor And Humor In Advertising". PhD, Texas Tech University, 1987.

Speck, Paul Surgi. "The Humorous Message Taxonomy: A Framework For The Study Of Humorous Ads". Current Issues and Research in Advertising 13, no. 1-2 (1991): 1-44.

Spotts, Harlan E., Marc G. Weinberger, and Amy L. Parsons. "Assessing The Use And Impact Of Humor On Advertising Effectiveness: A Contingency Approach". Journal of Advertising 26, no. 3 (1997): 17-32.

Sternthal, B., \& Craig, C. S.“Humor in advertising”. Journal of Marketing 37 (1973), 12 -18 .

Szabo, Attila. "The Acute Effects Of Humor And Exercise On Mood And Anxiety". Journal of Leisure Research 35, no. 2 (2003): 152-162.

VEATCH, THOMAS C. "A Theory Of Humor". Humor - International Journal of Humor Research 11, no. 2 (1998). 
Weinberger, Marc G., and Charles S. Gulas. "The Impact Of Humor In Advertising: A Review". Journal of Advertising 21, no. 4 (1992): 35-59.

Weinberger, Marc G., and Harlan E. Spotts. "Humor In U.S. Versus U.K. TV Commercials: A Comparison". Journal of Advertising 18, no. 2 (1989): 39-44.

WoltmanElpers, Josephine L. C. M., Ashesh Mukherjee, and Wayne D. Hoyer. "Humor In Television Advertising: A Moment-To-Moment Analysis". Journal of Consumer Research 31, no. 3 (2004): 592-598.

Zhang, Yong. "The Effect Of Humor In Advertising: An Individual-Difference Perspective". Psychology and Marketing 13, no. 6 (1996): 531-545. 